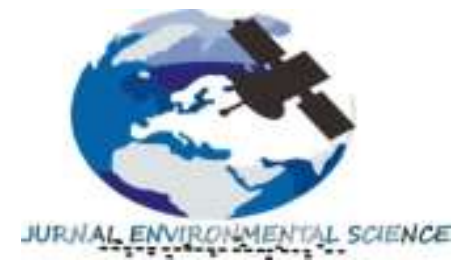

\section{PEMANFAATAN PENGINDERAAN JAUH DAN SISTEM INFORMASI GEOGRAFIS DALAM ANALISIS TINGKAT RAWAN KEKERINGAN LAHAN SAWAH DI KECAMATAN LABAKKANG}

\author{
Muh. Jibran Nidhal Fikri ${ }^{1}$, Rosmini Maru ${ }^{2}$ \\ ${ }^{12}$ Jurusan Geografi Fakultas Ilmu dan Pengetahuan Alam \\ Universitas Negeri Makassar \\ Email:*muhjibrannidhal@gmail.com ${ }^{1}$,rosmini.maru@unm.ac.id ${ }^{2}$
}

\begin{abstract}
The research aims to (1) determine the distribution of the drought-prone level of paddy fields in Labakkang District in 2021 and (2) analyze the dominant regional factors affecting the level of drought-prone rice fields in Labakkang District. The research method used in this study is a tiered quantitative method by combining primary data on Google Earth images in 2021 and secondary data on land use, slope, soil texture, soil solum and rainfall. Determination of the field survey using a stratified sampling method based on land units. The results of this study obtained a map of the level of vulnerability to drought in paddy fields. Rice fields in Labakkang District have an area of 3,675 hectares. The low level of drought susceptibility of lowland rice fields has a distribution in several areas, namely Taraweang Village, Barabatu Village, Batara Village, Kassi Loe Village, Patallassang Village, Labakkang Village and Mangalekkana Village. of the total area of rice fields, the majority are in technically irrigated rice fields with flat slopes. The level of drought-prone rice fields is moderately distributed in Taraweang Village, Pattallassang Village, Manakku Village, Kassi Loe Village, Kanaungan Village, Gentung Village, Batara Village, Bara Batu Village, Pundata Baji Village, Mangellakana Village, Labakkang Village, Borimasunggu Village. The classification of moderate drought-prone level has an area of 12,452 hectares with a percentage of 62.34\% of the total area of rice fields in the Labakkang sub-district and the majority is located in semi-technical and rain-fed irrigated rice fields with flat to gentle slopes and slightly smooth and rough texture. . The high level of drought-prone rice fields has a distribution in the areas of Mangalekkana Village, Kassi Loe Village and Kanaungan Village. Areas with a high level of drought-prone rice fields have the least compared to others with an area of 542 hectares with a percentage of $14.74 \%$ of the total area of rice fields in the Labakkang sub-district.
\end{abstract}

Keywords: Drought, Rice Fields, Labakkang District 


\section{PENDAHULUAN}

Kekeringan adalah salah satu bencana alam yang terjadi secara perlahan berlangsung lama hingga musim hujan tiba yang mempunyai dampak yang luas (Mujtahiddin, 2014). Kekeringan terjadi akibat adanya penyimpangan kondisi cuaca dari kondisi normal yang terjadi di suatu wilayah. Penyimpangan tersebut dapat berupa berkurangnya curah hujan dibandingkan dengan kondisi normal. Kekeringan erat kaitannya dengan berkurangnya curah hujan, suhu udara di atas normal, kelembaban tanah rendah, dan pasokan air permukaan yang tidak mencukupi (Wheaton, dkk, 1992).

Kekeringan sering terjadi di Indonesia, tetapi penangangan untuk pencegahan dan penanggulangan sangat lamban sehingga menjadi masalah berkepanjangan yang tidak terselesaikan (BAKORNAS PB, 2007). Kecamatan Labakkang merupakan salah satu daerah yang rawan terjadinya kekeringan, salah satunya adalah kekeringan pertanian. Hampir setiap tahun terdapat kasus kekeringan lahan sawah di beberapa wilayah di Kecamatan Labakkang, seperti data yang terekam oleh Dinas Pertanian Kabupaten Pangkajene dan Kepulauan (2015) Terdapat kasus kekeringan lahan pertanian yang terekam selama beberapa tahun terakhir puncaknya pada tahun 2015. Kekeringan lahan sawah paling besar terjadi pada tahun 2015 yang menyebabkan kerusakan lahan sawah ringan seluas 10 persen dari 12.000 lahan produktif atau sekitar 1.200 hektar yang tersebar di beberapa kecamatan yang ada di Pangkajene dan Kepulauan termasuk yang paling banyak di kecamatan labakkang.

Informasi mengenai kondisi keadaan permukaan sangat diperlukan, baik dalam bentuk data numerik maupun data spasial. Informasi spasial fisiografis wilayah dapat digunakan dalam mendeskripsikan kondisi permukaan sebagai langkah dalam merencanakan serta merekomendasikan pembangunan daerah (Raharjo, 2010). Perkembangan teknologi penginderaan jauh dan sistem informasi geografis yang sangat pesat saat ini membantu dalam menyediakan data sebagai informasi tentang kekeringan suatu wilayah. Penginderaan jauh memiliki kemampuan dalam memberikan informasi secara lebih cepat, cakupan daerah studi lebih luas serta kebutuhan biaya relatif lebih rendah untuk mendapatkan informasi mengenai terjadinya kekeringan (Hadi, dkk. 2016). Menurut Hounam dkk (1975) penentuan tingkat kekeringan bertujuan untuk mengevaluasi kecenderungan klimatologis menuju keadaan kering/tingkat kekeringn dari suatu wilayah, memperkirakan kebutuhan air irigasi pada suatu luasan tertentu, mengevaluasi kekeringan pada suatu tempat secara lokal, dan melaporkan secara berkala perkembangan kekeringan secara regional. Wilayah yang berpotensi terhadap kekeringan dapat diidentifikasi dengan mengaitkan berbagai parameter yang memicu terjadinya kekeringan tersebut.

Penelitian tentang kekeringan pertanian dengan menggunakan penginderaan jauh dan sistem informasi geografis seperti ini diharapkan mampu untuk menganalisis faktor wilayah yang berpengaruh terhadap kejadian kekeringan dan dapat menghasilkan peta tematik yang mampu menggambarkan kondisi lahan sawah, agar kerusakan akibat kekeringan dapat diminalisir.

\section{METODE}

Metode penelitian yang digunakan dalam penelitian ini adalah metode kuantitatif berjenjang dengan penggabungan data primer citra Google Earth tahun 2021 dan data sekunder. 
Penelitian ini dilakukan di Kecamatan Labakkang, Kabupaten Pangkajene dan Kepulauan. Metode analisis dalam penelitian ini menggunakan metode tumpang susun berjenjang digunakan untuk mengetahui tingkat rawan kekeringan lahan sawah di Kecamatan Labakkang dengan melakukan overlay pada parameter penentu tingkat rawan kekeringan lahan sawah.

Parameter tersebut diperoleh dari data primer berupa citra Google Earth tahun 2021 dan data sekunder berupa data kemiringan lereng, tekstur tanah, solum tanah, dan curah hujan yang diperoleh dari instansi terkait. Berikut parameter yang berpengaruh terhadap tingkat rawan kekeringan lahan sawah di Kecamatan Labakkang:

\section{Penggunaan Lahan Sawah}

Penggunaan lahan sawah merupakan parameter yang didapat melalui interpretasi langsung dari citra Google Earth tahun 2021 dan digabungkan dengan data guna lahan Kecamatan Labakkang. Penggunaan lahan terbagi menjadi 2 jenis, yaitu penggunaan lahan untuk sawah dan non sawah. Penggunaan lahan sawah dibagi lagi menurut teknik irigasinya. Semakin baik teknik irigasi semakin kecil berpotensi mengalami kekeringan, di Kecamatan Labakkang terbagi menjadi beberapa jenis teknik irigasi. Berikut Tabel 1 tentang klasifikasi dan harkat penggunaan lahan sawah.

Tabel 1. Klasifikasi dan Harkat Penggunaan Lahan Sawah

\begin{tabular}{|c|c|c|}
\hline No. & Klasifikasi Irigasi & Harkat \\
\hline 1 & Irigasi Teknis & 2 \\
\hline 2 & Semi Teknis & 3 \\
\hline 3 & Sederhana & 4 \\
\hline 4 & Tadah Hujan & 5 \\
\hline
\end{tabular}

Sumber: Puslittanak Bogor, 2002 dalam Vira Nami dengan modifikasi

\section{Kemiringan Lereng}

Parameter kemiringan lereng diperoleh dari data sekunder kelerengan dari instansi terkait. Kemiringan lereng memiliki kaitan terhadap tingkat kerawanan kekeringan lahan sawah, lereng pada suatu tempat berpengaruh terhadap besar kecil air yang terkandung didalam tanah. Semakin terjal lereng dapat dipastikan daerah tersebut cadangan airnya lebih sedikit jika dibandingkan dengan daerah yang memiliki kondisi lereng yang datar. Kecamatan Labakkang memiliki kemiringan lereng yang beragam, mulai dari datar, landai, agak curam, dan curam. Berikut Tabel 2 tentang klasifikasi dan harkat kemiringan lereng. 
Tabel 2. Klasifikasi dan Harkat Kemiringan Lereng

\begin{tabular}{|c|c|c|c|}
\hline No. & Kemiringan $(\%)$ & Klasifikasi & Harkat \\
\hline 1 & $0-8$ & Datar & 1 \\
\hline 2 & $>8-15$ & Lantai & 2 \\
\hline 3 & $>15-25$ & Agak Curam & 3 \\
\hline 4 & $>25-45$ & Curam & 4 \\
\hline 5 & $>45$ & Sangat Curam & 5 \\
\hline
\end{tabular}

Sumber: Sunarto Goenadi, dkk (2003

\section{Tekstur Tanah}

Tekstur tanah merupakan perbandingan fraksi pasir, debu dan liat yang terkandung pada tanah. Perbedaan komposisi pada tanah tersebut berpengaruh terhadap kemampuan meloloskan dan menahan air. Hubungan tekstur tanah dengan tingkat rawan kekeringan lahan sawah adalah mengenai daya serap tanah tersebut terhadap air. Tanah dengan tekstur yang kasar akan mudah meloloskan air karena memiliki banyak ruang pori-pori diantara partikel tanah tersebut, sehingga air yang terkandung dalam tanah akan lebih sedikit jumlahnya dan menjadi tidak subur. Sedangkan tanah dengan tekstur halus akan lebih lama dalam mengikat air karena partikel tanah sangat kecil dan mengisi seluruh ruang pada pori-pori tanah, sehingga air yang terkandung di dalamnya semakin banyak. Berikut Tabel 3 tentang klasifikasi dan harkat btekstur tanah.

Tabel 3. Klasifikasi dan Harkat Tekstur Tanah

\begin{tabular}{|c|c|c|c|}
\hline No. & Tekstur Tanah & Klasifikasi & Harkat \\
\hline 1 & Halus & $\begin{array}{c}\text { Lempung, Lempung Berpasir, } \\
\text { Lempung Berdebu }\end{array}$ & 1 \\
\hline 2 & Agak Halus & $\begin{array}{c}\text { Geluh Berlempung, Geluh } \\
\text { Lempung Berpasir }\end{array}$ & 2 \\
\hline 3 & Sedang & Geluh berdebu, Debu, Geluh & 3 \\
\hline 4 & Agak Kasar & Geluh Berpasir & 4 \\
\hline 5 & Kasar & Pasir, Pasir Bergeluh & 5 \\
\hline
\end{tabular}

Sumber: Dulbahri (1992)

\section{Solum Tanah}

Solum tanah merupakan salah satu faktor penentu tingkat kekeringan lahan sawah yang berhubungan dengan daya tampung air pada tanah. Solum tanah yang dalam memiliki kandungan air yang lebih banyak. Solum tanah seperti itu biasanya terdapat pada daerah yang memiliki kemiringan lereng yang relatif datar yang jarang terjadinya erosi tanah. Sedangkan untuk daerah yang memiliki kemiringan lereng yang terjal, solum tanahnya akan lebih dangkal dikarenakan tingginya erosi tanah yang terjadi, sehingga memiliki sedikit kandungan air. Parameter ini didapat dari penurunan jenis tanah dengan didasarkan pada pendekatan klasifikasi USDA. Setiap jenis tanah memiliki kedalaman tanah yang berbeda dan klasifikasi USDA menjelaskan semua itu secara jelas. Berikut Tabel 4 tentang klasifikasi dan harkat solum tanah. 
Tabel 4. Klasifikasi dan Harkat Solum Tanah

\begin{tabular}{|c|c|c|c|}
\hline No. & Solum Tanah & Klasifikasi & Harkat \\
\hline 1 & $>120$ & Sangat Dalam & 1 \\
\hline 2 & $90-120$ & Dalam & 2 \\
\hline 3 & $50-90$ & Sedang & 3 \\
\hline 4 & $25-50$ & Dangkal & 4 \\
\hline 5 & $<25$ & Sangat Dangkal & 5 \\
\hline
\end{tabular}

\section{Curah Hujan}

Sumber: Sunarto Goenadi, dkk (2003)

Hujan yang turun merupakan sumber dari ketersediaan air di daratan karena hujan merupakan unsur pokok dalam siklus hidrologi yang terus berulang. Curah hujan yang tinggi di suatu daerah akan mempengaruhi tingkat ketersediaan air di daerah tersebut. Daerah yang memiliki curah hujan yang tinggi maka akan terjadi kecil kemungkinan fenomena kekeringan. begitu pula sebaliknya apabila curah hujan yang turun semakin kecil atau bahkan tidak ada hujan dalam waktu yang lama maka besar kemungkinan akan terjadi kekeringan. Data curah hujan Kecamatan Labakkang didapat dari Dinas Pengairan dan memiliki rentang waktu selama 10 tahun mulai dari tahun 2008 sampai 2018. Berikut Tabel 5 tentang klasifikasi dan harkat curah hujan.

Tabel 5. Klasifikasi dan Harkat Curah Hujan

\begin{tabular}{|c|c|c|}
\hline No. & Rata-Rata Curah Hujan $(\mathrm{mm} / \mathrm{th})$ & Harkat \\
\hline 1 & $>3000$ & 1 \\
\hline 2 & $2501-3000$ & 2 \\
\hline 3 & $2001-2500$ & 3 \\
\hline 4 & $1501-2000$ & 4 \\
\hline 5 & $<1500$ & 5 \\
\hline
\end{tabular}

Sumber : Puslittanak Bogor, 2002 dalam Vira Nami dengan modifikasi

Formula yang digunakan dalam menentukan tingkat kerawanan kekeringan dapat dinyatakan dengan rumus sebagai berikut :

$$
\mathrm{TKK}=\mathrm{LS}+\mathrm{KL}+\mathrm{TT}+\mathrm{ST}+\mathrm{CH}
$$

Keterangan :

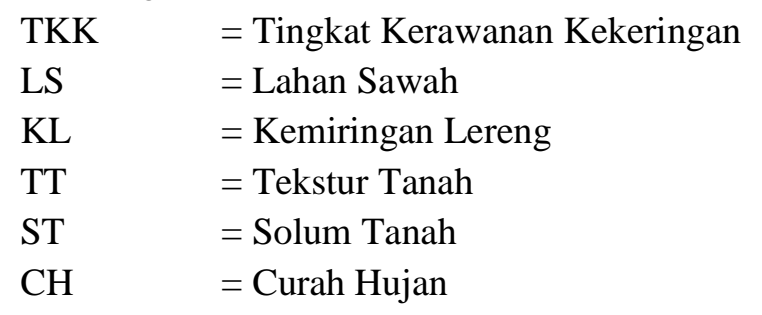

Parameter tingkat kerawanan kekeringan lahan sawah yang telah diberikan skor nilai kemudian dilakukan proses overlay dengan menggabungkan setiap parameter serta 
menjumlahkan masing-masing skor tersebut untuk menentukan tingkat kerawanan kekeringan. Hasil klasifikasi tingkat kerawanan kekeringan di Kecamatan Labakkang di bedakan menjadi 3 tingkat, yaitu tingkat kerawanan kekeringan rendah, sedang, dan tinggi, seperti yang terlihat pada Tabel 6 tentang kelas tingkat rawan kekeringan lahan sawah. Untuk mendapatkan interval kelas tingkat kerawanan kekeringan dapat menggunakan metode Sturges, sebagai berikut:

$$
\begin{aligned}
\text { Interval kelas }(\mathrm{Ci}) & =\frac{\text { skor maksimal-skor minimal }}{3} \\
& =\frac{12-5}{3} \\
& =2,33
\end{aligned}
$$

Tabel 6. Klasifikasi dan Harkat Solum Tanah

\begin{tabular}{|c|c|c|c|}
\hline No. & Kelas & $\begin{array}{c}\text { Tingkat Rawan Kekeringan } \\
\text { Lahan Sawah }\end{array}$ & Harkat \\
\hline 1 & I & Rendah & $5-7$ \\
\hline 2 & II & Sedang & $8-10$ \\
\hline 3 & III & Tinggi & $11-12$ \\
\hline
\end{tabular}

\section{HASIL DAN PEMBAHASAN}

\section{Hasil Penelitian}

Hasil penelitian merupakan peta yang dianalisis berdasarkan data dari tiap parameter yang berpengaruh terhadap tingkat rawan kekeringan lahan sawah di Kecamatan Labakkang sebagai berikut:

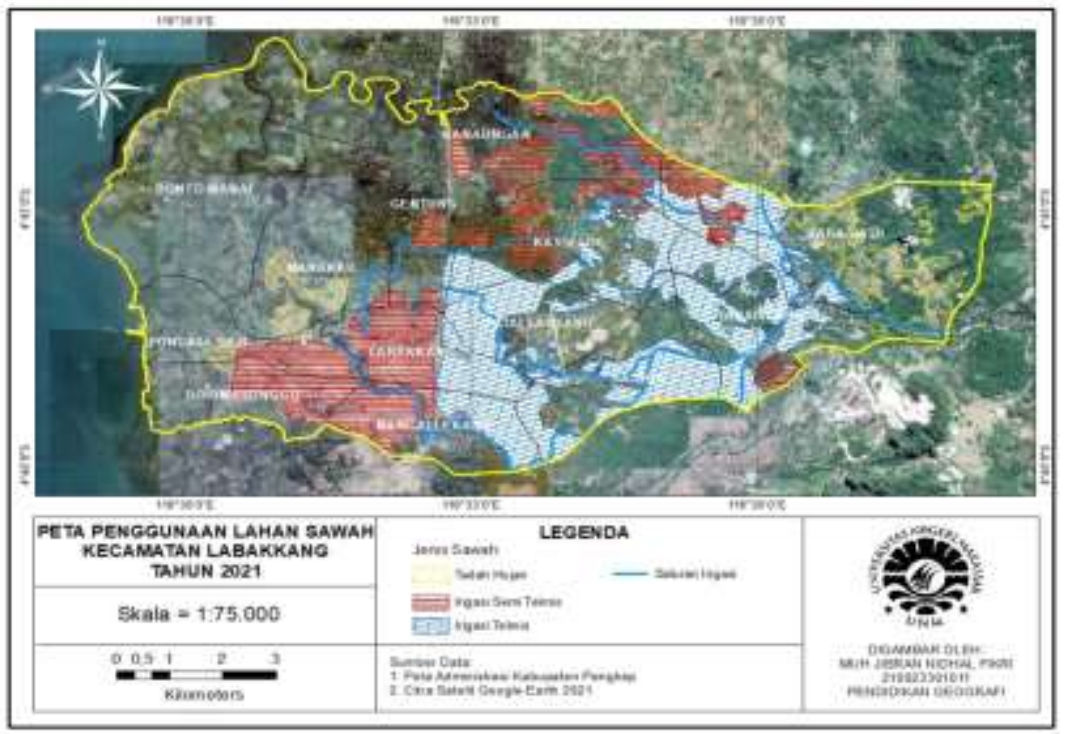

Gambar 1. Peta Penggunaan Lahan Sawah di Kecamatan Labakkang 
Berdasarkan hasil penelitian pada gambar 1 terkait parameter penggunaan lahan sawah di kecamatan labakkang diketahui luas sawah yang termasuk jenis sawah irigasi teknis yakni seluas 1.841 hektar dan sawah irigasi semi teknik dengan luas 1352 ha serta sawah tadah hujan dengan luas 482 hektar dengan luas total lahan sawah di kecamatan labakkang yakni 3.675 hektar.

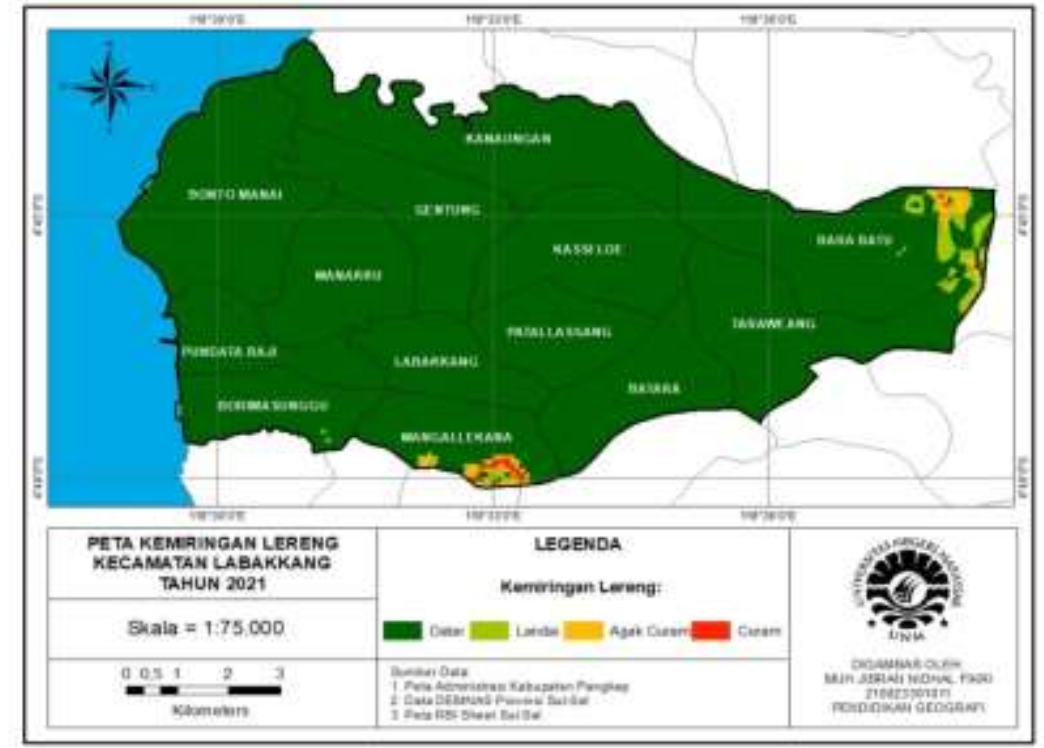

Gambar 2. Peta Kemiringan Lereng di Kecamatan Labakkang

Berdasarkan hasil penelitian pada gambar 2 terkait parameter kemiringan lereng di kecamatan labakkang diketahui luas wilayah yang termasuk dalam kategori datar seluas 9946 ha, kategori landai seluas 181 ha, kategori agak curam seluas 83 ha, dan kategori curam 20 ha. Lereng dengan kategori curam tersebar di Keluraha Mangalekkana dan Desa Barabatu.

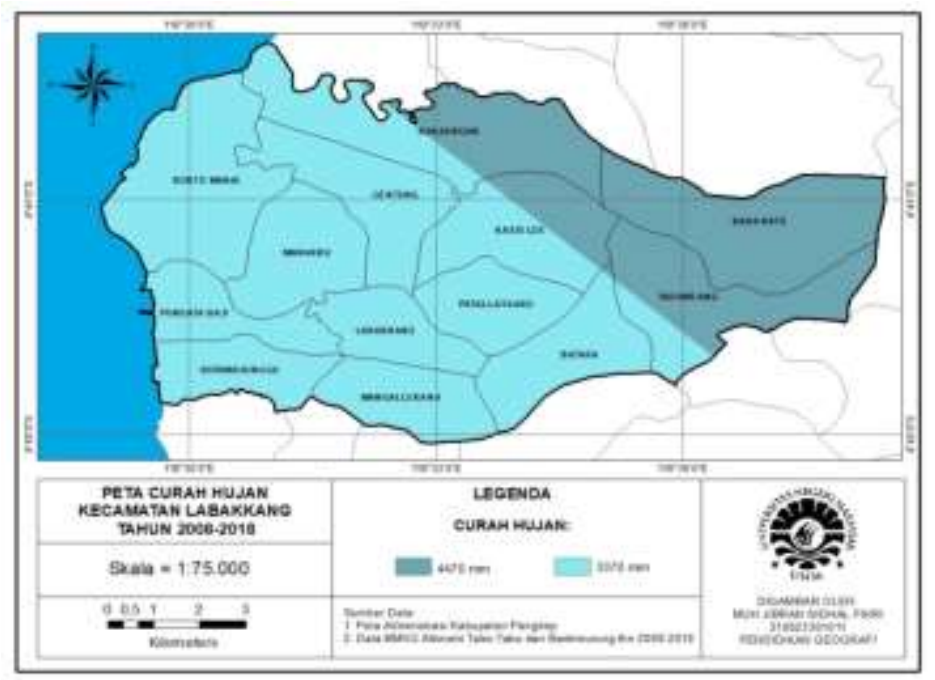

Gambar 3. Peta Curah Hujan di Kecamatan Labakkang 
Hasil analisa spasial curah hujan di kecamatan labakkang terlihat pada gambar 3, analisa spasial curah hujan dilakukan dengan data curah hujan BMKG altimetri Tabo-tabo dan Bantimurung tahun 2008-2018 dan ditemukan rata-rata jumlah curah hujan > $300 \mathrm{~mm}$ yakni sebesar $4470 \mathrm{~mm}$ dan $3370 \mathrm{~mm}$.

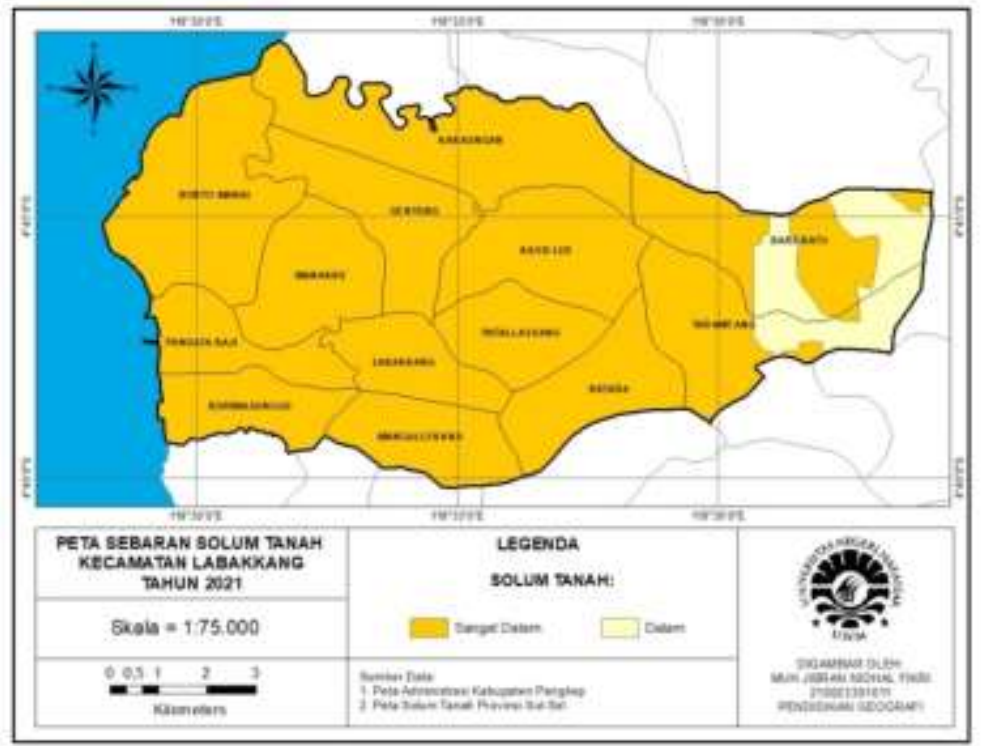

Gambar 4. Peta Solum Tanah di Kecamatan Labakkang

Berdasarkan hasil penelitian pada gambar 4 terkait parameter Solum Tanah di kecamatan labakkang diketahui bahwa kecamatan labakkang terdiri dari 2 jenis solum tanah yakni solum tanah dalam seluas 765 ha dan sangat dalam seluas 9416 ha. Sebaran solum tanah dangkal terdapat di Desa Barabatu dan Desa Taraweang.

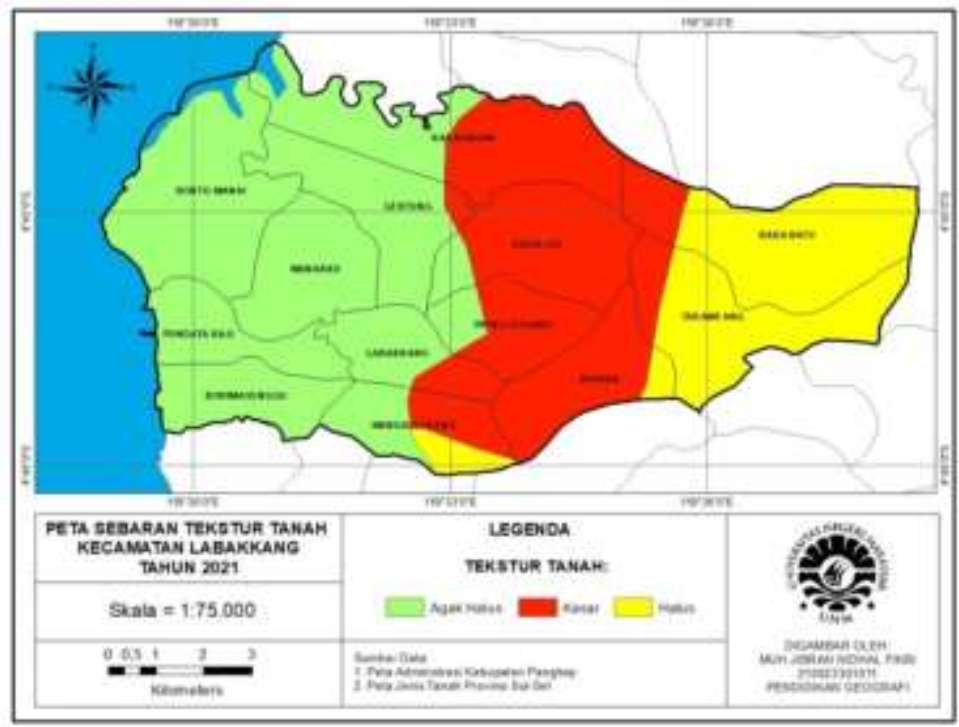

Gambar 5. Peta Tekstur Tanah di Kecamatan Labakkang 
Berdasarkan hasil penelitian pada gambar 5 terkait parameter Tekstur Tanah di kecamatan labakkang diketahui bahwa kecamatan labakkang terdiri dari 3 jenis tekstur tanah yakni tekstur tanah agak halus seluas 4944 ha, halus seluas 2026 ha serta kasar seluas 3103 ha. Sebaran tekstur tanah kasar terdapat di Desa Batara, Desa Kassiloe, Desa Patallassang dan Kelurahan Mangalekkana.

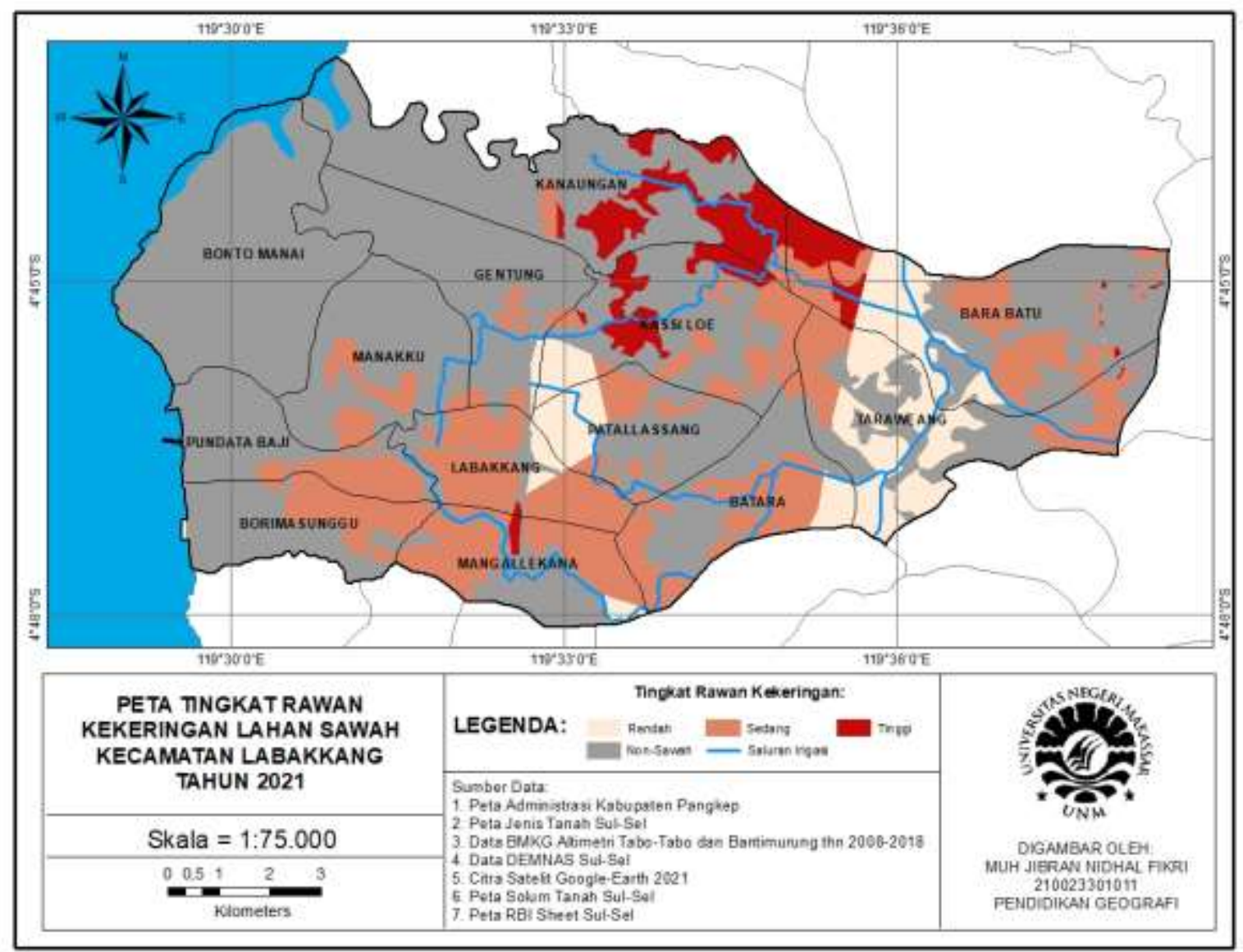

Gambar 6. Peta Tingkat Rawan Kekeringan Lahan Sawah di Kecamatan Labakkang

Berdasarkan hasil penelitian pada gambar 6, terkait tingkat rawan kekeringan lahan sawah di kecamatan labakkang setelah melalui overlay dari kelima parameter yang memengaruhi ditemukan bahwa tingkat rawan kekeringan lahan sawah di kecamatan labakkang terdiri dari 3 tingkatan yakni tingkat kerawanan rendah seluas 842 ha, tingkat kerawanan sedang seluas 2.291 ha serta tingkat kerawanan tinggi seluas 542 ha. Sebaran tingkat rawan kekeringan lahan sawah tinggi terdapat di Kelurahan Mangalekkana, Desa Kassiloe, dan Desa Kanaungan. 


\section{Pembahasan}

\section{Agihan Tingkat Rawan Kekeringan Lahan Sawah Di Kecamatan Labakkang Pada Tahun 2021}

Kekeringan pertanian merupakan gejala alam yang membuat sumber-sumber air untuk pemenuh kebutuhan hidup tanaman menipis atau bahkan mengering. Hal tersebut mengganggu pertumbuhan tanaman dan bisa membuat tanaman tersebut mati, sehingga dalam banyak kasus menyebabkan gagal panen. Kegagalan panen tersebut membuat kerugian besar bagi petani dan masyarakat lainnya yang memanfaatkan hasil panen untuk dikonsumsi. Kekeringan pertanian sering terjadi pada waktu musim kemarau tiba. Pada saat itu curah hujan yang turun sangat sedikit dan bisa dalam beberapa bulan tersebut tidak ada hujan sama sekali. Ketidaktentuan jatuh tempo musim penghujan dan musim kemarau membuat kerawanan kekeringan pertanian semakin meninggi.

Lahan sawah di Kecamatan Labakkang memiliki luas 3.675 hektar sedangkan sisanya 6.505 hektar merupakan lahan non sawah. Tingkat rawan kekeringan lahan sawah rendah memiliki persebaran di beberapa wilayah yakni Desa Taraweang, Desa Barabatu, Desa Batara, Desa Kassi Loe, Desa Patallassang, Kelurahan Labakkang dan Kelurahan Mangalekkana Tingkat rawan kekeringan lahan sawah rendah memiliki luasan sebesar 842 hektar dengan persentase $22,92 \%$ dari seluruh luas lahan sawah, mayoritas berada di satuan lahan sawah beririgasi teknis dengan lereng yang datar.

Tingkat rawan kekeringan lahan sawah sedang memiliki persebaran di Desa Taraweang, Desa Pattallassang, Desa Manakku, Desa Kassi Loe, Desa Kanaungan, Desa Gentung, Desa Batara, Desa Bara Batu, Kelurahan Pundata Baji, Kelurahan Mangellakana, Kelurahan Labakkang, Kelurahan Borinasunggu. Klasifikasi tingkat rawan kekeringan sedang memiliki luas wilayah 12.452 hektar dengan persentase $62,34 \%$ dari seluruh luas lahan sawah yang ada di kecamatan labakkang dan mayoritas terletak pada satuan lahan sawah beririgasi semi teknis dan tadah hujan dengan lereng datar hingga landai dan bertekstur agak halus dan kasar.

Tingkat rawan kekeringan lahan sawah tinggi memiliki persebaran di wilayah Kelurahan Mangalekkana, Desa Kassi Loe dan Desa Kanaungan. Wilayah dengan tingkat rawan kekeringan lahan sawah tinggi memiliki paling sedikit dibanding yang lain dengan luas sebesar 542 hektar dengan persentase $14,74 \%$ dari seluruh luas lahan sawah yang ada di kecamatan labakkang. Penyusun satuan lahan pada lahan sawah yang berkategori tingkat rawan kekeringan tinggi mayoritas berjenis sawah tadah hujan dan sawah irigasi semiteknis dengan variasi lereng yang beragam dari datar sampai agak curam dan tanahnya didominasi tekstur kasar. Daerah-daerah ini merupakan daerah yang memang menjadi langganan mengalami kekeringan lahan pertanian maupun kekeringan hidrologis. Untuk lebih jelasnya dalam mengetahui agihan tingkat rawan kekeringan lahan sawah dapat dilihat pada Gambar 6 di atas tentang peta tingkat rawan kekeringan lahan sawah di Kecamatan Labakkang tahun 2021. 


\section{Faktor-Faktor Wilayah Yang Dominan Mempengaruhi Tingkat Rawan Kekeringan Lahan Sawah Di Kecamatan Labakkang.}

Faktor wilayah yang mendominasi tingkat rawan kekeringan lahan sawah tertuju pada parameter penggunaan lahan sawah berdasarkan teknik irigasi yang dipakai dan parameter tekstur tanah. Kedua parameter tersebut memiliki nilai harkat maksimal yaitu 5 pada wilayah dengan tingkat rawan yang tinggi dibanding dengan parameter lainnya, sehingga kedua parameter ini memiliki dominasi penyebab kekeringan lahan sawah selama ini. Sawah tadah hujan merupakan jenis sawah yang mengandalkan curah hujan yang turun sebagai sumber air untuk pengairan sawah, apabila pada saat musim kemarau tiba sawah ini akan mengalami kekurangan air yang nantinya berdampak pada kesehatan tanaman sawah. Semakin lama dibiarkan maka akan membuat sawah tersebut mengalami kekeringan dan membuat tanaman mati.

\section{SIMPULAN}

Penelitian ini menghasilkan luaran berupa peta tingkat rawan kekeringan lahan sawah di Kecamatan Labakkang. Lahan sawah di kecamatan labakkang memiliki luas 3675 ha. Tingkat rawan kekeringan lahan sawah rendah memiliki persebaran di beberapa wilayah yakni Desa

Taraweang, Desa Barabatu, Desa Batara, Desa Kassi Loe, Desa Patallassang, Kelurahan Labakkang dan Kelurahan Mangalekkana Tingkat rawan kekeringan lahan sawah rendah memiliki luasan sebesar 842 hektar dengan persentase 22,92\% dari seluruh luas lahan sawah, mayoritas berada di satuan lahan sawah beririgasi teknis dengan lereng yang datar. Tingkat rawan kekeringan lahan sawah sedang memiliki persebaran di Desa Taraweang, Desa Pattallassang, Desa Manakku, Desa Kassi Loe, Desa Kanaungan, Desa Gentung, Desa Batara, Desa Bara Batu, Kelurahan Pundata Baji, Kelurahan Mangellakana, Kelurahan Labakkang, Kelurahan Borinasunggu. Klasifikasi tingkat rawan kekeringan sedang memiliki luas wilayah 12.452 hektar dengan persentase $62,34 \%$ dari seluruh luas lahan sawah yang ada di kecamatan labakkang dan mayoritas terletak pada satuan lahan sawah beririgasi semi teknis dan tadah hujan dengan lereng datar hingga landai dan bertekstur agak halus dan kasar. Tingkat rawan kekeringan lahan sawah tinggi memiliki persebaran di wilayah Kelurahan Mangalekkana, Desa Kassi Loe dan Desa Kanaungan. Wilayah dengan tingkat rawan kekeringan lahan sawah tinggi memiliki paling sedikit dibanding yang lain dengan luas sebesar 542 hektar dengan persentase 14,74\% dari seluruh luas lahan sawah yang ada di kecamatan labakkang. Faktor wilayah yang mendominasi tingkat rawan kekeringan lahan sawah tertuju pada parameter penggunaan lahan sawah berdasarkan teknik irigasi yang dipakai dan parameter tekstur tanah.

\section{DAFTAR RUJUKAN}

Badan Koordinasi Nasional Penanggulangan Bencana. 2007. Pengenalan Karakteristik Bencana Dan Upaya Mitigasinya Di Indonesia, edisi II. Penerbit : Direktorat Mitigasi Lakhar BAKORNAS PB. Jakarta. 
Badan Meterologi Klimatologi dan Geofisika. 2014. Prakiraan musim kemarau 2014. Badan Meteorologi Klimatologi dan Geofisika, Tahun 2014. http://www.bmkg.go.id/bmkg pusat/Sestama/Humas/prakiraan musim kemarau 2014 di indonesia.bmkg diakses 28 Oktober 2014.

Dinas Pertanian. 2013. Kasus Dampak Perubahan Iklim (Kekeringan) Lahan Sawah Kabupaten Sragen Tahun 2006 - 2013. Sragen

Dulbahri. 1992. Kemampuan Teknik Penginderaan Jauh Untuk Kajian Agihan dan Pemetaan Air Tanah di Daerah Aliran Sungai Progo. Disertasi. Fakultas Geografi UGM : Yogyakarta.

Goenadi, Soenarto dkk. 2003. Konservasi lahan Terpadu Daerah Rawan Bencana Longsoran Di Kabupaten Kulonprogo Daerah Istemawa Yogyakarta. Laporan Penelitian. Yogyakarta : Pusat Studi Bencana, Universitas Gadjah Mada.

Hadi, A. P., Danoedoro, P., \& Sudaryatno, S. (2016). Penentuan tingkat kekeringan lahan berbasis analisa citra aster dan sistem informasi geografis. Majalah Geografi Indonesia, 26(1), 1-26.

Hounam, C.E., Burgos, J.J., Kalik, M.S., Palmer, W.C., dan Rodda, J. (1975). Drought and Agriculture. Technical note no.138. World Meteorological Organization.

Mujtahiddin, M. I. (2014). Analisis Spasial Indeks Kekeringan Kabupaten Indramayu. Jurnal Meteorologi dan Geofisika, 15(2).

Raharjo, P. D. (2010). Teknik penginderaan jauh dan sistem informasi geografis untuk identifikasi potensi kekeringan. Makara Journal of Technology, 14(2), 150373.

Wheaton EE, Arthur LM, Chorney B, Shewchuk S, Thorpe J, Whiting J, \& Wittrock V. (1992). The prairies drought of 1988. Climatological Bulletin, 26, 188-205. 